\title{
Aplicabilidade do desenho universal em instalações sanitárias
} Applicability of universal design in sanitary facilities

Aplicabilidad del diseño universal en instalaciones sanitarias

Mariana de Barros Casagranda Akamine ${ }^{1}$

Camila Amaro de Souza ${ }^{2}$

${ }^{1}$ Mestranda em Desenvolvimento Local pela Universidade Católica Dom Bosco (UCDB). Pós-graduada em nível de especialização lato sensu em Design de Interiores pela UCDB, e em Reabilitação Ambiental Sustentável Arquitetônica

e Urbanística pela Universidade de Brasília (UnB). Arquiteta e urbanista pela Universidade Anhanguera-Uniderp. Atualmente docente no Centro Universitário Unigran Capital. E-mail: mariana_casagranda@yahoo.com.br, ORCID: http://orcid.org/0000-0001-9605-1061

${ }^{2}$ Doutora em Tecnologias Ambientais pela Universidade Federal de Mato Grosso do Sul (UFMS). Mestre em Climatologia Urbana. Graduada em Arquitetura e Urbanismo pela Universidade de Brasília (UnB). Experiência na área de Arquitetura e Urbanismo, com ênfase em Arquitetura Hospitalar, Gestão de Projetos em Engenharias e Arquitetura, Conforto Ambiental e Planejamento Urbano. E-mail: arq.camila.amaro@gmail.com, ORCID: https://orcid.org/0000-0002-1982-6895 
Resumo: O presente artigo tem como objetivo apresentar uma breve contextualização histórica das instalações sanitárias, a partir das principais obras que tratam do assunto, com foco na sua evolução, e associá-las à aplicabilidade do desenho universal, demonstrando a importância delas na otimização dos espaços e na inclusão social. A pesquisa de referência bibliográfica foi desenvolvida com base em material publicado em livros, revistas, jornais e redes eletrônicas, para produzir uma análise descritiva sobre o tema proposto, pois se acredita que os projetos de instalações sanitárias hoje já solucionaram questões como higiene, execução e manutenção, materiais de acabamento e revestimento e até mesmo questões energéticas, que, por sua vez, estão sendo cada vez mais exploradas neste ambiente tão dinâmico. Os novos projetos, de maneira geral, tendem a buscar, neste momento, mais versatilidade, integração e respeito à diversidade, estimular e viabilizar a independência, de maneira a construir uma sociedade centrada no indivíduo.

Palavras-chave: integração; acessibilidade; desenho universal.

\begin{abstract}
This article aims to present a brief historical contextualization of sanitary facilities, from the main works that deal with the subject, focusing on its evolution, and to associate them with the applicability of universal design, demonstrating their importance in the optimization of spaces and social inclusion. The bibliographic reference research was developed based on material published in books, magazines, newspapers, and electronic networks, to produce a descriptive analysis on the proposed theme, since it is believed that the sanitary facilities projects today have solved issues such as hygiene, execution, and maintenance, finishing and coating materials and even energy issues, which, in turn, are increasingly being explored in this dynamic environment. New projects, in general, tend to seek more versatility, integration, and respect for diversity, stimulate and enable independence, in order to build an individual-centered society.
\end{abstract}

Keywords: integration; accessibility; universal design.

Resumen: Este artículo tiene como objetivo presentar una breve contextualización histórica de las instalaciones sanitarias, a partir de los principales trabajos que abordan el tema, centrándose en su evolución, y asociarlas con la aplicabilidad del diseño universal, demostrando la importancia de ellas en la optimización de espacios y la inclusión social. La investigación de referencia bibliográfica se desarrolló en base a material publicado en libros, revistas, periódicos y redes electrónicas, para producir un análisis descriptivo sobre el tema propuesto, ya que se cree que los proyectos de instalaciones sanitarias de hoy en día han resuelto problemas como la higiene, la ejecución y mantenimiento, materiales de acabado y recubrimiento e incluso problemas de energía, que, a su vez, se exploran cada vez más en este entorno dinámico. Los nuevos proyectos, en general, tienden a buscar una mayor versatilidad, integración y respeto por la diversidad, estimulan y permiten la independencia para construir una sociedad centrada en el individuo.

Palabras clave: Integración; accesibilidad; diseño universal. 


\section{INTRODUÇÃO}

O estudo das nossas edificações, assim como sua organização espacial e usos, são de extrema importância para a compreensão de uma determinada cultura.

Os populares banheiros, conhecidos também como instalações sanitárias, são espaços indispensáveis em qualquer edificação destinada ao uso humano, e seu estudo é primordial para sua concepção. Hoje em dia, utilizar-se de um banheiro é algo tão corriqueiro, que parece que sempre foi assim, mas não. Os sanitários que conhecemos hoje, do ponto de vista histórico, tecnológico, funcional, entre outros aspectos, surgiram recentemente. O banho diário, assim como dispor de água encanada, é um costume recente.

O presente estudo traz um breve histórico das instalações sanitárias, citando autores que descrevem os registros dos primeiros banheiros, com suas principais características, tais como mobiliários, materiais construtivos, acabamentos e revestimentos, sistemas hidráulicos, localização espacial e a cultura da higiene, ou até mesmo a falta dela, ao longo dos séculos no mundo.

O texto cita também dados gerais, aspectos legais e normatizações, de modo a elucidar questões como o direito das pessoas com deficiência ao uso dos espaços coletivos de maneira segura e confortável, e o avanço dessas normatizações, como a atualização da NBR 9050 em 2020, trazendo melhorias quanto à concepção das instalações sanitárias. Relaciona, ainda, o conceito de acessibilidade à ergonomia, para então discutir os termos segregação, integração e acessibilidade.

Destaca-se também o período histórico de início da exclusão social de pessoas com deficiência, para discutir a segregação e seus reflexos na sociedade. Desta forma, é importante frisar que o conceito de integração, que incorpora indivíduos e cria uma sociedade única, vai ao encontro da acessibilidade, gerando resultados positivos, de forma a contribuir para o desenvolvimento social.

Neste contexto, a discussão sobre desenho universal é atual e indispensável, pois este ainda é frequentemente confundido com acessibilidade, limitando-se apenas ao cumprimento das normas vigentes. 
Assim, a aplicabilidade do desenho universal de maneira consciente e inteligente produz soluções ambientais, as quais são capazes de proporcionar o aumento da autonomia dentro do espaço construído, por meio de projetos que compreendam e respeitem a diversidade.

\section{BREVE HISTÓRICO DAS INSTALAÇÕES SANITÁRIAS}

As instalações sanitárias, conhecidas popularmente como banheiros, são primordiais e indispensáveis na composição dos espaços construídos de uso humano, mas nem sempre foi assim.

Moutinho, Prado e Londres (1999) afirmam que o termo banheiro trata-se da "peça de casa destinada à higiene corporal e equipada com os diferentes aparelhos necessários para tal fim". Quanto ao seu uso, o espaço destinado ao banheiro é constatado desde os tempos remotos.

Segundo Zabalbeascoa (2013), para se conhecer a história da civilização, basta realizar uma análise de suas batalhas ou até mesmo a observação dos seus hábitos privados.

Ainda conforme a autora, as instalações sanitárias, popularmente chamadas de banheiros, até o século XX não tinham uma localização fixa dentro das moradias. Diferentemente de outros ambientes da casa, a história do banheiro não segue uma linha progressiva: existem épocas limpas e sujas, ou seja, há culturas que favorecem a limpeza, outras supostamente pudicas. Antes mesmo de ser associado à limpeza, o banheiro foi relacionado à saúde, ao prazer e a rituais de purificação.

O banho diário é um costume recente. Assim como dispor de água encanada. Até meados do século XX, boa parte dos lares ocidentais não viu torneiras e encanamentos. Sabe-se que historicamente as pessoas, quando se lavavam, faziam-no por partes e, muitas vezes, longe de suas casas. Ao longo da oscilante história, esse espaço recebeu diversos nomes, como: privada, latrina, quarto de banho, sanitário, entre outros, até ser um cômodo que merece destaque nas casas de hoje.

Neste contexto, pode-se afirmar que os rios foram ao mesmo tempo as primeiras banheiras e os mais primitivos esgotos. Desde a Antiguidade, a mesma corrente de água serve tanto para o banho e o consumo quanto 
para carregar os dejetos e excrementos.

Quando as margens dos rios se povoaram e deixaram de admitir novos moradores, o asseio da população diminuiu. Nas comunidades assentadas longe dos rios, os banhos deixaram de ser frequentes, até que a água chegou por outras vias com a instituição de criados (ou escravos) ou a instalação dos encanamentos, segundo os contextos e as épocas (ZABALBEASCOA, 2013, p. 25).

Um dos primeiros banheiros de que se tem registro é o da rainha de Cnossos. Construído em um anexo ao seu quarto no palácio de Creta, tinha banheiras, executadas abaixo do nível do solo, às quais era possível acessar por meio de degraus. O palácio de Cnossos contava com encanamentos de terracota cônicos, para evitar o acúmulo de sedimentos, além de uma rede de esgoto e fossas de pedra. Conforme Zabalbeascoa (2013), seu descobrimento pelo arqueólogo britânico Arthur Evans revelou que os cretenses superaram os egípcios e os gregos em engenharia hidráulica.

Ainda conforme a autora, no século IV a. C., além de higiênicos, os banhos se tornaram uma prática social. Os romanos, futuramente, viriam a construir banheiros com grandes janelas, as quais tinham a função de entrar luz e calor do sol para aquecer a água. Algo que a Europa não viu até o século XVIII.

Na Mesopotâmia, esse espaço era conhecido como quarto de banho, dispunha de uma banheira que ocupava todo o cômodo. Pode-se destacar a presença de materiais como gessos, tijolos e mosaicos. Os babilônicos eram menos habituados ao banho que os egípcios. Os gregos depositavam a água em grandes vasilhas instaladas em pedestais e localizadas nas entradas dos ginásios, para se lavarem ao ar livre. Porém foi Roma que sofisticou os banhos e associou saúde e limpeza a prazer.

No ano 19 a. C., na antiga Roma, foi inaugurada uma era de banhos públicos que acabou com a escassez de balneários. Construiu-se um aqueduto para levar água até as termas. A partir de então, era aquecida por meio de um sistema de circulação de água quente entre muros. Na época, Roma dispunha de treze aquedutos, quase quinhentos quilômetros de dutos (ZABALBEASCOA, 2013).

Para Mumford (1982), a contribuição mais marcante de Roma, tanto à higiene urbana quanto à forma urbana, foi o banho, apontando em relatos 
históricos os grandes banhos em termas, que acomodavam milhares de banhistas.

Zabalbeascoa (2013) afirma ainda que o espaço mais íntimo foi tradicionalmente o lugar inexistente ou exposto em uma moradia: os banhos eram mais públicos que privados.

Preocupados com a estética do espaço, imperadores e arquitetos competiam na sofisticação dos interiores. Cúpulas altas somaram-se à decoração das paredes, à qualidade das colunas ou à qualidade escultural das cornijas. Com o objetivo de unir o estético com o funcional, os mosaicos eram um dos acabamentos mais usados, retratando a fauna local, deuses e até cenas corriqueiras da vida pública.

Após a queda do Império Romano, a higiene sofreu um retrocesso na Europa que duraria quase mil anos.

No período medieval, a higiene e a limpeza ficaram restritas aos mosteiros. Nos mosteiros, as latrinas apresentavam assentos de madeira e eram construídas com divisões laterais para garantir a privacidade. Quando não se exigia a clausura, havia uma janela atrás dos vasos, para facilitar a ventilação e a iluminação. As tubulações medievais eram executadas com lâminas de chumbo soldadas ou troncos de olmo ocos.

Leonardo da Vinci imaginou uma privada com assento dobrável e giratório e outra que utilizava água corrente para se livrar dos detritos. Mas não teria imitadores nem seguidores. De modo que, por séculos, seus inventos foram considerados excentricidades que, em muitos casos, não chegaram a se desenvolver até o século XX, o da democratização do banheiro e do asseio (ZABALBEASCOA, 2013, p. 31).

Até o século XVI, era comum compartilhar a tina de banho. Este período foi considerado uma das épocas mais escuras e sujas da história, em que o asseio caiu em profundo declínio e assim perdurou por quase dois séculos. Durante o século XVII, a falta de preocupação com higiene ainda predominava, as ruas transformaram-se em esgotos, esvaziavam-se pelas janelas bacias com água suja e urinóis. Com a rede de água e esgoto coberta e a pavimentação, a higiene melhorou na maioria das moradias, nas quais, por meio de canos de olmo unidos com ferro ou chumbo, começava a chegar água. 
As primeiras privadas abastecidas com água corrente chegaram ao século XVIII no Castelo de Windsor, na Inglaterra. Essas primeiras peças que contavam com água corrente eram artefatos de pedra esculpida ou chumbo fundido, os quais empregavam a água por meio de um mecanismo de êmbolo. Esses primeiros modelos possibilitavam o escape da água, pois a válvula submergida não fechava hermeticamente o recipiente. Zabalbeascoa (2013) afirma ainda que só em 1775 foi patenteada uma privada de reservatório elevado que mantinha a água no vaso e permitia esvaziá-lo a cada uso. O sistema foi utilizado durante mais de um século e, em 1778, Joseph Bramah patenteou a primeira privada moderna.

O banheiro foi um cômodo itinerante. No século XVIII, mudava com os usos, do quarto à cozinha, dependendo do tipo de moradia. Os primeiros designers dos quartos de banho foram os moveleiros, que buscavam mais disfarçar o uso dos parelhos que facilitá-lo. Neste século, o objetivo era camuflar, como a mesa-bidê ou a poltrona-privada.

No século XIX, alguns rios urbanos transforam-se em esgotos e, consequentemente, fonte de infecções, pois os dejetos, até então, podiam ser vendidos como adubo, mas, à medida que as cidades cresceram, o transporte tornou-se não rentável.

O desenvolvimento da ciência fez com que a higiene voltasse a ser levada em conta. Quando o costume do asseio se propagou novamente, as banheiras de mármore deram lugar às metálicas, mais baratas e leves, porém, apesar dos avanços, as instalações das banheiras também foram feitas gradativamente.

Essas banheiras não eram ligadas a nenhum encanamento. A água transportada por meio de dutos perdia boa parte da sua temperatura; desta forma, até meados do século XIX, eram os aguadeiros, com suas carroças de água quente, que levavam os banhos aos domicílios, nas principais cidades europeias.

O banheiro com encanamento, pioneiro na América, chegou à Casa Branca em 1851.

Quando finalmente as tubulações chegaram aos edifícios, tornou-se necessário encontrar um lugar para os banheiros nas casas. No início, foram instalados nos porões, ou na parte posterior das moradias, pela 
dificuldade de fazer com que a água subisse pelos canos. Mas não foram as moradias a realizar experimentos com a água corrente, e sim os hotéis (ZABALBEASCOA, 2013, p. 39).

O primeiro passo para a instalação do banheiro fixo foi a possibilidade de levar água quente diretamente à banheira. Foi apresentado na Grande Exposição de Londres, em 1851, um dos primeiros sistemas de aquecimento. Nessa mesma exposição, pela primeira vez, instalaram-se privadas públicas. No final do século XIX, um dos primeiros aquecedores a gás já contava com um aquecedor de toalhas, e a água já chegava quente - fatos que redesenhariam a história do banheiro.

No Brasil, assim como na Europa, a implantação de redes de água e esgoto nas cidades ocorreu no século XIX, atendendo os domicílios. Os banhos de bacia, jarras de quarto e urinóis, que estavam sujeitos às dificuldades do transporte, obtiveram melhor definição funcional e técnica (VERÍSSIMO; BITTAR, 1999).

Com a chegada da água corrente, a bacia foi embutida no mármore e transformou-se em pia. Os aparelhos eram embutidos, mas os canos continuavam expostos. As banheiras passaram a ser fixas, surgindo, assim, os primeiros banheiros superdimensionados, o que acabaria por mudar quando se preferiu trocar um banheiro grande por vários menores.

O banheiro moderno se firmou com a chegada da industrialização, quando os vasos, os lavatórios e as banheiras de porcelana esmaltada passaram a ser produzidos em série. Vale destacar a evolução dos materiais de acabamentos e revestimentos, que passaram a ser laváveis e não porosos, os quais se transformaram em ideais de limpeza.

Le Corbusier definiu o lar moderno como aquele que adotava as normas higiênicas proporcionadas pelo banheiro (ZABALBEASCOA, 2013, p. 45). A imagem da modernidade era representada pela sobriedade dos banheiros, em que a tecnologia impunha-se sobre a tradição.

A generalização do uso desses espaços e de suas instalações fez com que as cidades aos poucos fossem se adaptando. Os banheiros começaram a ter melhor otimização dos espaços, associando-se à economia eà eficácia. Surgiram privadas dobráveis e móveis de duplo uso. Apesar de a moda ser o conforto, durante todo o século XX, havia a distinção entre o luxuoso, confortável e básico. 
Segundo Veríssimo e Bittar (1999), durante os anos de 1970, os banheiros ganharam cor, remodelando completamente o velho banheiro, dando ênfase à funcionalidade. Nesse mesmo período, surgem as "suítes" em residências unifamiliares e apartamentos.

Em 1972, sugiram as torneiras de monocomando, que misturavam água fria e quente, e que também permitiam o controle do fluxo. Pouco tempo antes, havia surgido a torneira que permitia variações na pressão da ducha por meio do giro. As duchas de pressão variável permitiam regular a força da água e sua quantidade, o que possibilitou o primeiro passo para o controle da energia.

Com toda a evolução ocorrida nos anos de 1980, o banheiro passou a ser considerado um dos cômodos mais importantes da casa, não tanto pela sua função, mas pelo seu valor representativo, o que acabou por gerar, mais recentemente, uma maior preocupação com a economia energética.

Os projetos atuais apontam para um aumento da versatilidade e para novos usos do cômodo. Nas residências mais ambiciosas, busca transformar-se no quarto da saúde, unindo em um único espaço primeiros socorros, higiene e esporte. Já nos apartamentos pequenos o banheiro continua sendo o quarto de despejo no qual acabam por ser instalados - para aproveitar o escoamento da água - os eletrodomésticos (máquinas de lavar ou secadoras) que não cabem em outro lugar. A recuperação do banheiro como um espaço para o exercício e a saúde, a redução do tamanho de seus elementos - que tornará possível um número maior de instalações por moradia e, portanto, maior privacidade no seu uso - e, sobretudo, a economia energética surgem como os novos desafios do banheiro para o século XXI (ZABALBEASCOA, 2013, p. 51).

Os novos desafios em relação à economia energética citada pela autora ficam evidentes se analisarmos o crescimento populacional acelerado e o desenvolvimento industrial e tecnológico ao longo das últimas décadas, os quais vêm comprometendo os recursos naturais disponíveis. Nesse contexto, Mota, Manzanares e Silva (2006) afirmam que a água passa a ser um recurso estratégico para a expansão da indústria. Os autores mencionam ainda que um terço da água potável utilizada dentro das casas vai diretamente para os ralos, e que a maioria dessa água é utilizada nos chuveiros. 
Desta forma, Mota, Manzanares e Silva (2006) mencionam que uma alternativa para o problema pode ser o reúso da água doméstica, com a utilização de materiais baratos e um sistema simples para o reaproveitamento da água do chuveiro e vaso sanitário. Os autores destacam ainda que a grande vantagem da utilização da água de reúso é a de preservar água potável para atendimento de necessidades que exigem a sua potabilidade, como para a ingestão direta ou preparo de alimentos. Assim, a gestão dos recursos hídricos por meio do reúso e da conservação da água passa a ser mais uma etapa da história evolutiva das instalações sanitárias, atendendo ao apelo mais atual quanto à sustentabilidade.

\section{DADOS GERAIS, ASPECTOS LEGAIS E NORMATIZAÇÕES}

A Organização das Nações Unidas (ONU) declarou 1981 como o Ano Internacional das Pessoas com Deficiência. Segundo o Instituto Brasileiro de Geografia e Estatística (IBGE), no Censo Demográfico de 2010, 45.606.048 brasileiros, 23,9\% da população total, têm algum tipo de deficiência. Com isso, o tema ganhou destaque, fortalecendo o que na época denominava-se extinção das barreiras arquitetônicas.

Com base nesse dado expressivo, justifica-se a grande importância de projetar, também para essa parcela da população, espaços que os atendam de maneira segura e confortável.

Segundo o Art. $5^{\circ}$ da Constituição Federal, todos são iguais perante a lei, sem distinção de qualquer natureza, garantindo-se aos brasileiros e aos estrangeiros residentes no País a inviolabilidade do direito à vida, à liberdade, à igualdade, à segurança e à propriedade (BRASIL, 1988).

Nos últimos anos, observa-se um avanço na promoção dos direitos das pessoas com deficiência, por meio das políticas públicas. Segundo o Governo Federal, a partir dos anos de 1960, houve uma politização do tema, o que acarretou uma maior visibilidade e importância da questão para a sociedade em geral.

Desta forma, desde a Constituição Federal de 1988, o assunto foi definitivamente inserido no marco legal e, a partir de então, vêm sendo promulgadas diversas leis que abrangem o tema. 
Segundo o Ministério da Mulher, da Família e dos Direitos Humanos (MDH), em 1985 foi criada a primeira Norma Técnica pertinente à acessibilidade, intitulada ABNT NBR 9050, que dispunha sobre a adequação das edificações, equipamentos e mobiliário urbano à pessoa com deficiência (BRASIL, 2018a).

Cabe destacar que a normatização em questão foi criada antes mesmo da promulgação da Constituição Federal de 1988, o que reforça o fato de que o tema em discussão não é atual. Tendo em vista que tal norma é de interesse social, a ABNT firmou acordo com o Ministério Público Federal em junho de 2004, para a divulgação, pela Internet ou pelo Diário Oficial, das normas em referência, a fim de permitir o acesso amplo e irrestrito por qualquer cidadão interessado. A primeira revisão da NBR 9050 foi em 1994, e a última revisão realizada pela ABNT aconteceu em 2020.

A NBR 9050/2020 estabelece critérios e parâmetros técnicos a serem observados quanto ao projeto, construção, instalação e adaptação do meio urbano e rural, e de edificações às condições de acessibilidade. A norma em questão considera diversas condições de mobilidade e de percepção do ambiente, com ou sem a ajuda de aparelhos específicos. Visa, ainda, proporcionar a utilização de maneira autônoma, independente e segura do ambiente, edificações, mobiliário, equipamentos urbanos e elementos à maior quantidade possível de pessoas independente de idade, estrutura ou limitação de mobilidade ou percepção.

Nicholl e Boueri Filho (2001) definem como um objeto acessível aquele que pode ser alcançado para uso, e que, uma vez alcançado seu uso seguro e autônomo, não se trata mais de uma questão de acessibilidade, e sim de usabilidade. Os autores afirmam ainda que o conceito de usabilidade vai além da facilidade de utilização e pode ser mais bem caracterizado como o conjunto da facilidade de utilização e de aprendizagem, junto da eficácia, eficiência e satisfação que os usuários podem atingir.

Diretamente ligada à questão da acessibilidade, a ergonomia tem como principal objetivo desenvolver e aplicar técnicas de adaptação do homem aos espaços de forma eficiente e segura, viabilizando uma maior autonomia e bem-estar. O campo da ergonomia pode-se dividir em físico, 
cognitivo e organizacional, porém o presente estudo se restringirá aos conceitos da ergonomia física. O conceito em questão está relacionado às características da anatomia humana, antropometria, fisiologia e biomecânica em sua relação à atividade física. Envolve também o estudo da postura, manuseio de materiais, movimentos, segurança, saúde, entre outros.

\section{SEGREGAÇÃO, INTEGRAÇÃO E ACESSIBILIDADE}

A sociedade tem o compromisso com as maiorias e sua diversidade, e não somente com as pessoas com deficiência.

Segundo Yngaunis (2012), pode-se considerar como o marco de início da exclusão a Idade Antiga, época em que se valorizava a beleza, a capacidade física e o vigor, considerados de extrema importância para a sociedade agrária e guerreira.

O Período Clássico é marcado pelo pensamento de Platão e Aristóteles, que defendiam a exclusão dos "imperfeitos".

Ainda conforme a autora, na Idade Média a deficiência passou a ser interpretada sob os dogmas religiosos, e era considerada como castigo de Deus ou oportunidade para a prática da caridade. As pessoas com deficiência começaram a ser recolhidas pela igreja e abrigadas em instituição. Foi quando se iniciou o período da segregação.

Do latim segregatio, o termo segregação é a ação e o efeito de segregar, separar, marginalizar ou afastar algo ou alguém de outras coisas ou pessoas.

Yngaunis (2012) afirma ainda que, retirando as pessoas com deficiência do convívio social, tira-se da sociedade a oportunidade de construir um mundo preparado para incluir todas as pessoas, criando-se a falsa ideia de invisibilidade. Os recursos arquitetônicos de acessibilidade, por exemplo, como rampas, foram pensados a partir da análise das necessidades das pessoas com deficiência em acessar espaços e se locomover de maneira autônoma.

A segregação pode se refletir no acesso a recursos como emprego, sistema de saúde, educação, habitação, entre outros.

Na Idade Moderna, surgiu o conceito de reabilitação, que buscava minimizar o impacto negativo que a deficiência tinha sobre a relação social do indivíduo. 
Quando se transfere o foco do indivíduo para a sociedade, mobilizando recursos e competências para promover a inserção de pessoas com deficiência na vida social e econômica, inicia-se a inclusão social (YNGAUNIS, 2012).

O termo integração tem origem no latim integrare, que significa tornar inteiro. Desta forma, o significado da palavra está diretamente ligado ao ato de assimilar e reunir, de tornar alguém integrado em um grupo ou sociedade. O conceito de integração é bastante amplo, abrange diversas áreas e, por isso, pode ter significados distintos.

Para a sociologia, refere-se ao ato de incorporar totalmente os indivíduos em um país, cidade, comunidade, grupo, proporcionando a criação de uma sociedade única. Ou seja, a integração social é o processo que faz a inserção de pessoas ou grupos na sociedade.

Atrelada aos termos mencionados anteriormente, a acessibilidade, segundo o MDH, é um atributo essencial do ambiente que garante a melhoria da qualidade de vida das pessoas (BRASIL, 2018b). Deve estar presente nos espaços, no meio físico, no transporte, na informação e comunicação, inclusive nos sistemas e nas tecnologias da informação e comunicação, bem como em outros serviços e instalações abertos ao público ou de uso público, tanto na cidade como no campo.

O MDH afirma ainda que a acessibilidade gera resultados sociais positivos e contribui para o desenvolvimento inclusivo e sustentável, destacando que sua implementação é fundamental, porém, depende de mudanças de atitude e culturais. A sociedade como um todo deve trabalhar de forma a inserir medidas apropriadas para assegurar o acesso, em igualdade de oportunidades com as demais pessoas. Tais medidas podem incluir a identificação de barreiras à acessibilidade e a disseminação do conceito de desenho universal.

\section{O DESENHO UNIVERSAL E SUA APLICABILIDADE}

Interligado aos conceitos citados anteriormente, o desenho universal ou desenho para todos tem o objetivo de conceber objetos, equipamentos e estruturas do meio físico destinados a todos, buscando simplificar o cotidiano, independentemente da idade, estrutura ou capacidade, tornando os 
produtos, estruturas e edificações utilizáveis pelo maior número de pessoas possível, para que não só as que têm necessidades especiais, mas todas, sem exceção, possam integrar-se totalmente a uma sociedade inclusiva.

Segundo Carletto e Cambiaghi (2008), o debate no Brasil em torno do conceito de desenho universal iniciou-se de forma tímida em 1980, com o objetivo de conscientizar profissionais da área da construção.

O desenho universal, por ser um tema bastante recente no Brasil e ainda pouco aplicado, costuma ser frequentemente confundido com acessibilidade, o que resulta, erroneamente, no cumprimento automático das normas vigentes. A NBR 9050/2020 limita-se a espaços públicos de uso comum, desta forma, acaba gerando legislações no âmbito municipal e estadual, que contemplam os demais espaços.

A partir do entendimento prévio das necessidades de cada um dos indivíduos, o desenho universal busca conceber espaços que podem ser utilizados por qualquer pessoa em qualquer momento da vida, com conforto, segurança e integração.

Segundo o Governo do Estado de São Paulo, na década de 1990, um grupo de arquitetos e defensores de uma arquitetura e design mais centrados no ser humano e sua diversidade reuniu-se no Center for Universal Design, da Universidade da Carolina do Norte, nos Estados Unidos, a fim de estabelecer critérios para que edificações, ambientes internos, urbanos e produtos atendessem um número maior de usuários. Esse grupo definiu os sete princípios do desenho universal, os quais passaram a ser mundialmente adotados e o presente estudo toma como diretriz. São eles: uso equitativo; uso flexível; uso simples e intuitivo; informação de fácil percepção; tolerância ao erro (segurança); esforço físico mínimo; dimensionamento dos espaços para acesso e uso abrangente.

Neste sentido, as instalações sanitárias merecem mais atenção, pelo fato de hoje serem um espaço segregador dentro das edificações, muito provavelmente, em virtude de nossas normas e legislações cobrarem um desenho minimamente inclusivo, fazendo com que sejam necessárias diferentes unidades em um único espaço, com configurações diferentes, para que todos os usuários possam desfrutá-lo. 
Vale ressaltar que Zabalbeascoa (2013) menciona que Lawrence Wright, um historiador britânico, em meados do século passado já discutia a história do banheiro, defendendo que é possível saber mais sobre a história da humanidade pelo estudo dos seus banheiros do que pela análise de batalhas.

Ainda segundo esta autora, a economia energética é um novo desafio do banheiro para o século XXI, pois os projetos atuais apontam para o aumento da versatilidade e para novos usos do cômodo. Desta forma, desperta-se a importância de inserção de todos a um mesmo ambiente, de maneira a otimizar os espaços dentro da edificação, trazendo uma evolução para o desenho, não somente na questão energética, mas também aliando os diferentes conceitos, mencionados anteriormente, a fim de atingir um novo patamar na concepção desses espaços.

\section{O BANHEIRO INCLUSIVO E O DESENHO UNIVERSAL}

Kowaltowski e Bernardi (2005) afirmam que o desenho universal é o projeto de produtos, ambientes e comunicação a ser usado pelas pessoas em condições de igualdade, podendo ser chamado também de projeto inclusivo, projeto para todos e projeto centrado no homem.

Segundo Campos (2009), o banheiro está entre os locais mais importantes e caros de uma edificação, além de ser uma das áreas onde mais se tem a preocupação com projeto e tecnologia.

Neste contexto, Campos (2009) aborda conceitos como: banheiro inclusivo, segurança e independência dos usuários. E afirma que segurança e independência são dois importantes objetivos para projetos de banheiros. Cita ainda o protótipo Universal Home, de autoria da arquiteta Sandra Perito, doutora na aplicação do desenho universal pela Faculdade de Arquitetura da Universidade de São Paulo. Ela, por sua vez, considera todo banheiro como área molhada, e não apenas o box, tornando, assim, o espaço mais seguro e funcional, no que se pode chamar de "banheiro inclusivo".

Um dos maiores desejos do indivíduo é a aquisição ou construção da casa própria. A população brasileira está envelhecendo e anseia por moradias que proporcionem conforto e segurança a todos os usuários. Desta forma, a população tem cada vez mais buscado uma moradia que atenda 
a suas necessidades em diferentes momentos da vida, a casa para a vida toda, garantindo, portanto, autonomia e independência dos moradores em qualquer fase da vida.

O projeto de ambientes e produtos que possam ser usados por todos, com conforto e segurança, independentemente das habilidades, capacidade física ou idade, chama-se universal design.

O universal design segue alguns princípios básicos: a busca pela independência, possibilitando que as pessoas usem o ambiente e produtos com autonomia; a acessibilidade, pois todos devem se locomover sem dificuldade, sem barreira no ambiente; o espaço deve ser frequentável por visitantes, tendo em vista que todo ambiente construído é utilizado por grupos que usam e que visitam; o ambiente deve ser adaptável, ou seja, o ambiente de uso diário deve atender às necessidades individuais e, para isso, deve ser flexível e ter a possibilidade de se adaptar; os ambientes e produtos devem ser seguros a todos, independentemente da idade, limitação, e em qualquer circunstância; seu uso deve ser simples e intuitivo; deve tolerar erros sem consequências graves; os ambiente e produtos devem permitir ao usuário conforto e segurança durante as atividades; os ambiente e produtos devem ser esteticamente agradáveis e estar atrelados ao conceito arquitetônico da edificação; e, por fim, os produtos não devem ser especiais, mas sim de uso generalizado por todos, o que os tornam acessíveis financeiramente.

Desta forma, Campos (2009), afirma que a especialista propõe cinco elementos críticos incorporados em projetos de banheiros: espaço vazio embaixo da pia; previsão para instalação de barras de apoio; piso antiderrapante; box acessível e seguro; metais de uso facilitado.

Os conceitos do design universal sugerem algumas características que podem ser incorporadas nos projetos de banheiros: uso de torneiras e registros de pressão e alavanca, de um quarto de volta ou monocomando, pois exigem menor esforço para manuseio; instalação de registros na entrada do banheiro, para permitir regulagem da temperatura da água do chuveiro do lado externo do box, evitando escaldamento; abertura de portas do box para fora, com pelo menos $80 \mathrm{~cm}$ de vão, possibilitando o acesso da cadeira higiênica e para facilitar o socorro em caso de emergência; desnível de $2 \mathrm{~cm}$ 
em rampa entre o piso do banheiro e do box, evitando o transbordamento e barreiras; uso de textura e cor entre o piso do banheiro e do box para facilitar a identificação por pessoas com baixa acuidade visual; instalação de cubas de sobrepor, evitando que cedam, no caso de se apoiar nelas; instalação de barras de apoio fixas no box e ao lado da bacia sanitária, facilitando a mobilidade independente; colocação de espelhos baixos, grandes ou com inclinação para facilitar a visualização por crianças ou pessoas sentadas; previsão de instalações de telefone, interfone ou botão do pânico.

Por fim, Campos (2009) destaca ainda que, segundo a arquiteta Sandra Perito, os profissionais da área, como arquitetos e engenheiros, ainda desconsideram quase que totalmente o envelhecimento ou qualquer outo tipo de limitação presente nos usuários dos seus projetos, o que acaba por resultar em projetos com escadas e desníveis em abundância, sem preocupação com a acessibilidade.

O projeto de arquitetura pode e deve contribuir para minimizar as barreiras arquitetônicas que dificultam a acessibilidade (KOWALTOWSKI; BERNARDI, 2005, p. 160).

Desta forma, os projetos que considerem as mudanças fisiológicas, físicas, sensoriais e psíquicas do homem, baseados nos princípios do desenho universal, produzem boas soluções ambientais, capazes de aumentar a autonomia do usuário, além de permitir que as adaptações aconteçam naturalmente, com facilidade e custo reduzido.

\section{CONCLUSÃO}

Com base no estudo de todo o contexto histórico apresentado, destaca-se que a evolução das instalações sanitárias ocorreu, principalmente, pela necessidade, que prevaleceu em relação à preocupação estética. Isso se confirma com a análise do banheiro moderno, que recentemente ganhou destaque e importância em termos de inovação de layout, com novas tecnologias, funções e tamanhos.

Com a evolução do ambiente, atrelada às necessidades das pessoas, demonstra-se a grande importância de se projetar espaços que atendam de maneira segura e confortável diferentes parcelas da população, não só 
pessoas com deficiência, mas com qualquer tipo de limitação ao uso de espaços e produtos.

Assim, os conceitos como segregação, integração, acessibilidade e, principalmente, desenho universal, também conhecido como desenho para todos, que busca conceber objetos, equipamentos e estruturas do meio físico destinados a todos, quando aplicados às instalações sanitárias, objetivam simplificar o cotidiano, independentemente da idade, estrutura ou capacidade, tornando os produtos e as estruturas utilizáveis pelo maior número de pessoas possível, sem exceção, de forma que possam integrar-se totalmente a uma sociedade inclusiva.

Desta forma, o presente artigo visa alertar a sociedade e profissionais para a busca de espaços mais versáteis, por meio de projetos que compreendam e respeitem a diversidade, estimulando e viabilizando a independência, de maneira a construir uma sociedade centrada no indivíduo.

\section{REFERÊNCIAS}

ASSOCIAÇÃO BRASILEIRA DE NORMAS TÉCNICAS. NBR 9050: Acessibilidade à edificação, mobiliário, espaços e equipamentos urbanos. Rio de Janeiro: ABNT, 2020.

BRASIL. Ministério da Mulher, da Família e dos Direitos Humanos. Associação Brasileira de Normas Técnicas. Brasília-DF: MDH, 2018a. Disponível em: https:// www.gov.br/mdh/pt-br/navegue-por-temas/pessoa-com-deficiencia/normasabnt-1/associacao-brasileira-de-normas-tecnicas. Acesso em: 10 mar. 2021.

BRASIL. Ministério da Mulher, da Família e dos Direitos Humanos. Acessibilidade. Brasília-DF: MDH, 2018b. Disponível em: https://www.gov.br/mdh/pt-br/naveguepor-temas/pessoa-com-deficiencia/programas/acessibilidade. Acesso em: 10 mar. 2021.

BRASIL. Constituição da República Federativa do Brasil. Brasília-DF: Senado Federal, 1988.

CAMPOS, Iberê M. Banheiro inclusivo e universal design: projeto arquitetônico com acessibilidade. Bengala Legal, Rio de Janeiro, 2009. Disponível em: http:// www.bengalalegal.com/banheiro. Acesso em: 20 jun. 2017. 
CARLETTO, Ana Claudia; CAMBIAGHI, Silvana. Desenho universal: um conceito para todos. [Realização Mara Gabrilli]. São Paulo: [s.n.], 2008.

KOWALTOWSKI, Doris C. C. K.; BERNARDI, Núbia. Reflexões sobre a aplicação dos conceitos de desenho universal no processo de arquitetura. In: ENCAC- ENCONTRO NACIONAL, 8., ENCONTRO LATINO-AMERICANO SOBRE CONFORTO NO AMBIENTE CONSTRUÍDO, 4., Maceió, AL, out. 2005. Anais [...]. Maceió: ENCAC, 2005. p.15563. Vol. 1.

MOTA, Marcos B. Rezende; MANZANARES, Marina Dastre; SILVA, Rafael Augusto Lima. Viabilidade de reutilização de água para vasos sanitários. Revista Ciências do Ambiente On-Line, Campinas, v. 2, n. 2., p. 24-29, ago. 2006. Disponível em: http:// cmapspublic2.ihmc.us/rid=1255625139769_626372840_13304/RCA-OL-2006-57. pdf. Acesso em: 17 jun. 2017

MOUTINHO, Stella Rodrigo Octávio; PRADO, Rúbia Braz Bueno; LONDRES, Ruth Rodrigo Octávio. Dicionário de artes decorativas e decoração de interiores. Rio de Janeiro: Nova Fronteira, 1999.

MUMFORD, Lewis. A cidade na história: suas origens, desenvolvimento e perspectivas. São Paulo: Martins Fontes, 1982.

NICHOLL, Anthony Robert Joseph; BOUERI FILHO, José Jorge. O ambiente que promove a inclusão: conceitos de acessibilidade e usabilidade. Assentamentos Humanos, Marília, v. 3, n. 2, p. 1-80, dez. 2001. Disponível em: http://www.unimar. br/publicacoes/assentamentos/assent_humano3v2/Antony\%20e\%20jose.htm. Acesso em: 17 jun. 2017.

VERÍSSIMO, Francisco Salvado; BITTAR, William Seba Mallmann. 500 anos da casa no Brasil: as transformações da arquitetura e da utilização do espaço da moradia. Rio de Janeiro: Ediouro Publicações S. A., 1999.

YNGAUNIS, Sueli. Exclusão, segregação, reabilitação e inclusão: como as organizações podem construir uma nova história? Blog Comunicação Essencial, set. 2012. Disponível em: https://syngaunis.wordpress.com/2012/09/02/exclusaosegregacao-reabilitacao-e-inclusao-como-as-organizacoes-podem-construir-umanova-historia/. Acesso em: 20 jun. 2017.

ZABALBEASCOA, Anatxu. Tudo sobre a casa. São Paulo, 2013. 
